\title{
Are plain verbs really plain?: Co-localization as the agreement marker in sign languages
}

\author{
Guilherme Lourenço (Universidade Federal de Minas Gerais) \& \\ Ronnie B. Wilbur (Purdue University) \\ guilhermelourenco@ufmg.br, wilbur@purdue.edu
}

\begin{abstract}
In contrast to previous discussions on agreement, this paper argues that matching of location is the single morphological exponent of verb agreement in sign languages, using data from Brazilian Sign Language (Libras). Therefore, we reject the analysis of path and/or directionality as agreement markers. We argue that "plain" verbs are actually capable of showing agreement, as long as there is no phonological restriction, if we consider the sharing of location features (co-localization) as the sole agreement mechanism. Agreement is not restricted to a subset of verbs and is actually more pervasive and productive than has been argued, thus challenging one argument against calling it agreement.
\end{abstract}

Keywords: morphosyntax, verb agreement, layering of visual information, Brazilian Sign Language

\section{Introduction}

Agreement in sign languages has usually been described as a change in orientation and direction of movement of the verb (Mathur and Rathmann 2012, p. 137). We propose, however, that the sole manifestation of agreement in Libras - and possibly other sign languages - is not directionality, nor facing. It is, instead, the sharing of location features (loci) between controller (nominal) and target (verb), a process we call co-localization. The path movement in the so-called agreeing verbs is actually related to the event properties of the predicate, as consistently argued by Wilbur $(2008,2010)$ and others. Considering co-localization as the exponent of agreement allows us to treat plain verbs as agreeing constructions; because if plain verbs can take location features from a controller, they are actually showing agreement.

In order to build our claim, this paper is organized as follows. In Section 2, we discuss how agreement has been described in previous studies and we map these descriptions to the internal structure of the verb, assuming the Prosodic Model (Brentari 1998). In Section 3, we present our claim that co-localization is the sole agreement marker in Libras and, possibly, in other signed languages too. A discussion on the layering of visual information within the verb structure is provided in Section 4. Finally, in Section 5, some final remarks are outlined.

\section{The description of agreement in sign languages}

Once there are locations (geometrical points in space $(p)$ linked to specific referential individuals ( $x$ ) assigned to nominals), a group of verbs can be modified in such a way that the 
beginning point and the endpoint of their movement will coincide with the location associated to their arguments. This systematic modification of the verb based on the locations of its arguments has been called verb agreement. This is the case, for example, of the verb HELP in Libras (Figure 1). Notice that the verb HELP starts at the location assigned to JOHN and moves to the location associated to MARY. The interpretation of the sentence is that the beginning location of the verb marks the subject and the endpoint indicates the object. Additionally, the palm of the dominant hand faces towards the location of the object MARY.

Figure 1: JOHNa a HELP $\mathrm{JARY}_{\mathrm{b}}$

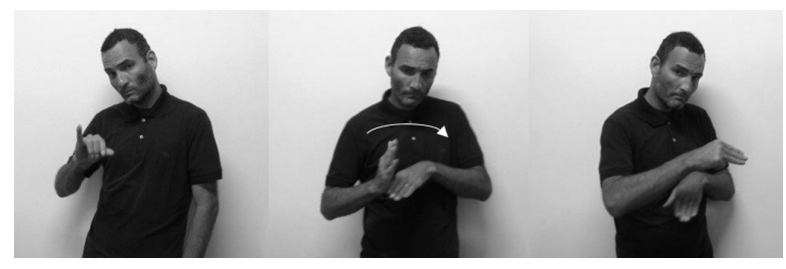

HELP is a canonical example of what has been called an 'agreement verb' in a sign language. This is so, because it exhibits the three main characteristics that have been identified as exponents of agreement in the current literature, to wit: i) a path movement; ii) movement from the subject's location toward the object's location; and iii) facing toward the syntactic object (see Figure 2). This is how, for example, Sandler and Lillo-Martin describe verb agreement in ASL (American Sign Language):

A verb which agrees will generally make use of the referential space by using the locus for the subject as the beginning location of the verb, and the locus of the object as the ending point. In signing the verb, then, the hand moves from the locus of the subject to the locus of the object. In addition, the direction in which the hands are facing is also generally affected in agreeing forms.(Sandler and Lillo-Martin 2006, emphases added by L\&W).

Figure 2: A visual representation of regular agreement in sign languages. The verb exhibits a movement from location (a) to location (b) and the palm of the (dominant) hand faces $(\mid>)$ towards location $(b)$.

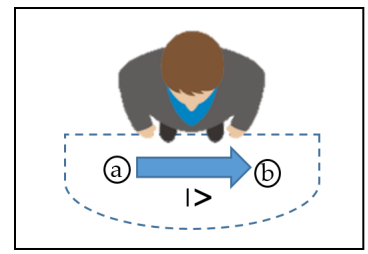

Although these three components have been claimed to mark verb agreement, the only one that is traditionally cited is the path movement (Table 1 ).

In addition to the description of the agreement marking in the manual domain, Bahan (1996) and Neidle et al. (2000) argue that nonmanual markers are also part of the agreement system in sign languages. Bahan (1996) claims that head tilt and eye-gaze are another possibility of subject and object agreement. Neidle et al. (2000, p. 75) go even further and claim that "agreement can be expressed nonmanually in clauses containing verbs without overt 


\section{Movement (Path) Location (points) Facing}

Padden (1988, p. 27)

Meir (1998a, p. 15)

Neidle et al. (2000, p. 33)

Fischer and Hulst (2003, p. 320)

Sandler and Lillo-Martin (2006, p. 27)

Quadros and Quer (2008, p. 531)

Mathur and Rathmann (2010, p. 173)

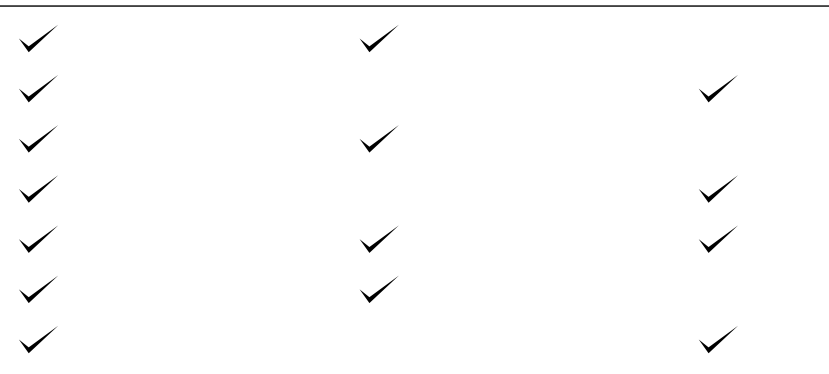

Table 1: The description of agreement in sign languages.

[manual] morphological agreement inflection" (but see Thompson, Emmorey, and Kluen$\operatorname{der}(2006))$.

Although there is some general consensus in assuming that the path movement is an agreement marker, the roles of location and facing are still debatable. For instance, there are some analyses that treat the facing of the hand(s) as a different agreement mechanism (Meir 1998a, 2002; Pfau, Salzmann, and Steinbach 2011).

One important consideration we want to point out is related to the internal structure of the verb. Assuming a very simplified version of the Prosodic Model (Brentari 1998), we can identify four main components or nodes in the phonological structure of the sign: the non-manual articulators; the manual articulators; the place of articulation (location); and the prosodic features (movement). If we compare that structure with the agreement markers that have been identified in the literature, we end up assuming that agreement changes the internal structure of the verb as a whole (Figure 3):

Figure 3: Internal structure of the verb and claimed targets of morphological modification for agreement marked by red circles.

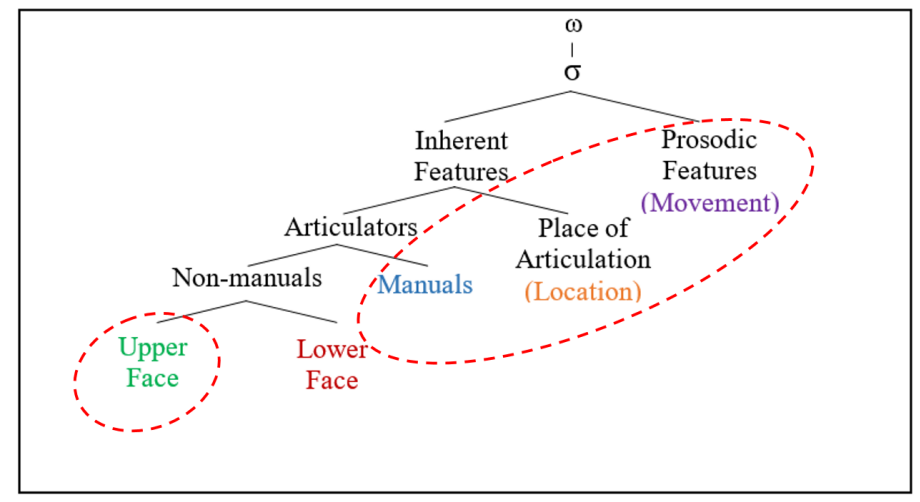

One of the main corollaries of these descriptions is that they create the notion of "agreement classes", as introduced by Padden (1988). That means that there is a group of verbs that shows agreement and a group of verbs that does not (plain verbs) ${ }^{1}$. The idea of agreement classes also brings up the question of what features predict that a verb will show agreement or not,

\footnotetext{
${ }^{1}$ In Padden (1988)'s analysis there are three distinct verb groups: agreement verbs (that she calls inflection verbs), plain verbs and spatial verbs. Quadros (1999) and Quadros and Quer (2008) differently argue that there
} 
and what is the nature of these features (phonological, semantic, syntactic?). Padden (1988), for instance, takes a lexical approach, claiming that agreement is lexically specified. Janis (1995) postulates a hierarchy based on the grammatical relation of the arguments and also their semantic roles, in order to predict agreement. Meir (2002), on the other hand, offers a semantic/thematic approach, in which the thematic roles of the arguments determine the agreement pattern. There is also an analysis based on animacy of the arguments (Rathmann and Mathur 2002). What we observe here is that the notion of agreement classes comes along with the notion of 'candidacy for agreement' and a need to predict which verbs will bear agreement morphology and which will not.

Additionally, it has been claimed that agreement in signed languages is somewhat different from agreement in spoken languages, because "the agreement process in sign languages is restricted to a smaller set of verbs, whereas agreement in spoken languages, if it is marked at all, is usually marked on the whole set of verbs" (Mathur and Rathmann 2012, p. 152). Under this perspective, agreement does not seem to be the rule, but the exception. This has led some researchers to claim that this process is not agreement at all, but a fusion of morphemic and deictic gestural elements (Liddell 2000, 2011) ${ }^{2}$.

Although it seems that agreement is everywhere in the internal structure of the verb and is restricted to a subset of verbs, we argue that these descriptions are inaccurate. Instead, our claim is that agreement is expressed solely by the sharing of the location specification of the argument(s) with the verb. That being so, we will demonstrate that the so-called "plain" verbs are actually capable of bearing agreement, in such a way that agreement is the rule not the exception. This is the topic of the next section.

\section{Co-localization as the agreement marker}

Let us start by analyzing the following example from Libras (see also Figure 4): ${ }^{3}$

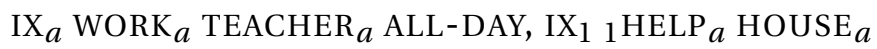

'She works as a teacher all day. So, I help her with the house.'

In this example, the verb WORK is considered a plain verb because it does not move from the locus of the subject to the locus of the object. There is no [direction] movement at all. On the other hand, the verb HELP is a typical agreement verb. It goes from the 1st person locus to the locus associated with the 3rd person $\mathrm{IX}_{\mathrm{a}}$ (she). This analysis is correct, if we consider that a [direction] type of movement is what marks agreement in sign languages. However, the verb WORK is not signed in a "neutral" space. The verb is pronounced on the same locus where the subject was marked. Why does the verb need to match the location of the subject?

Fischer and Gough (1978) already noticed this verb behavior in ASL and they called this process "locationality": "a third way a verb sign may show its grammatical relations is in displacement of the dez [handshape], as what acts, to the proximity of the location of one of

is no need to distinguish between agreement and spatial verbs, claiming that both show the same type of underlying agreement mechanism.

${ }^{2}$ But see Lillo-Martin and Meier (2011), Quer (2011) and Wilbur (2013) for strong argumentation against the gestural analysis.

${ }^{3}$ Notice that the indexical pronoun ( $\mathrm{IX}_{\mathrm{a}}$ ) is associated to a specific point in space - a locus - and not only the verb, but also other elements seem to agree with this locus: the adverb-like modifier TEACHER and the possessed nominal HOUSE. These other agreement processes are out of the scope of this paper, but we certainly would analyze them as true agreement, once they are also instances of co-localization. Therefore, sign languages seem to exhibit more than just verb agreement, akin to languages like Swahili in the Bantu family. 
Figure 4: $\mathrm{IX}_{\mathrm{a}}$ WORK $_{\mathrm{a}}$ TEACHER $\mathrm{a}$ ALL-DAY / IX ${ }_{1}$ HELP $_{\mathrm{a}}$ HOUSE $_{\mathrm{a}}$. 'She works as a teacher all day. So, I help her with the house'.

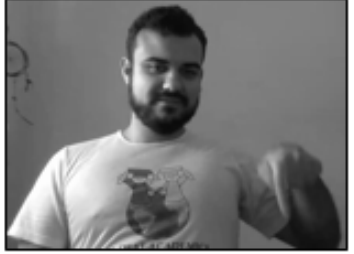

$\mathrm{IX}_{\mathrm{a}}$

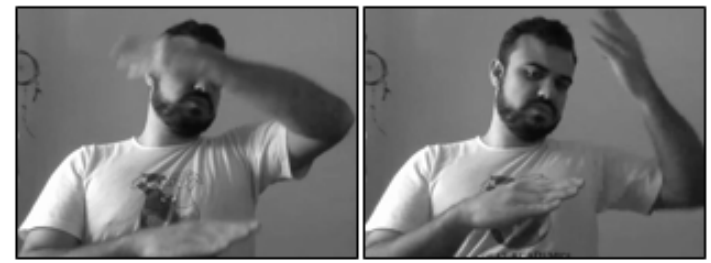

ALL-DAY

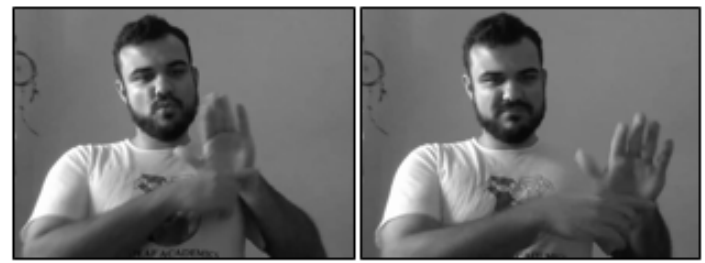

${ }_{1}$ HELPa

WORK $_{\mathrm{a}}$
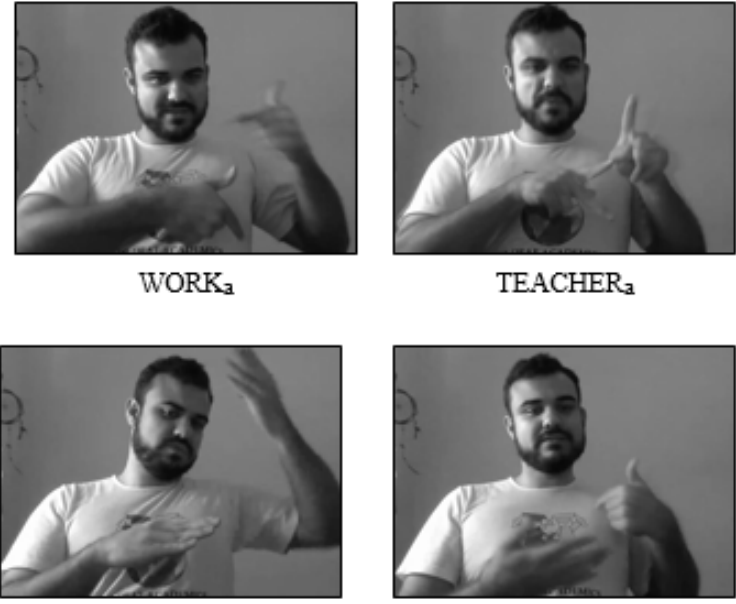

$\mathrm{IX}_{1}$

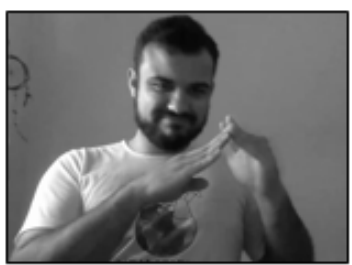

HOUSE $_{a}$

its arguments" (Fischer and Gough 1978, p. 30). The fact that plain verbs can be "localized" to match the locus of an argument is also attested by Bergman (1980), Costello (2015), Smith (1990), and others.

Our claim is that the matching of location is actually the true morphological realization of agreement in sign languages. If this is so, the verb WORK in Libras must be considered an agreeing verb.

Costello (2015, p.128), following Bergman (1980) adopts the term localization to describe the mechanism by which "a sign is articulated at a specific point in the signing space". We then call co-localization the output of the agreement operation that shares the location specification of the controller with the goal.

A quick look at the Libras Corpus (Quadros et al., n.d.) gives us plenty of examples of "plain" verbs that are co-localized in space, matching the locus of their arguments (Figure 5).

Figure 5: Plain verb signs in Libras (PUT-UP-WITH, STUDY, EXPLAIN, WORK and PLAY) displaying agreement with the locus of the controller (extracted from the Libras Corpus:

Quadros et al., n.d.).
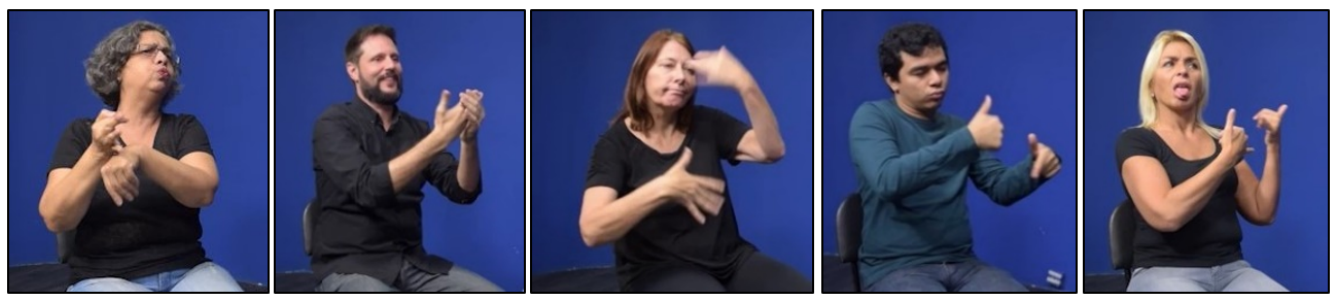
Co-localization as agreement is also true for the canonical agreeing verbs, like the verb HELP. What changes is what we consider to be the morphological exponent of agreement on the verb. It is not the directional path of movement that marks the agreement, but the matching of the location of the beginning point and the end point of the verb to the location of its arguments. The path movement in the so-called agreeing verbs is actually related to the event properties of the predicate, as consistently argued by Wilbur $(2008,2010)$ and others, as we will further elaborate in Section 3.3.

Based on the notion of location as the agreement marker, we propose the following definition for verb agreement:

(2) Definition of verb agreement in sign languages:

A verb shows agreement with its argument(s) when the location of the verb is changed in order to match the location of the argument(s), a process called co-localization.

Once we have a different definition for agreement, we need to go back to the previous classification of verbs and the classical distinction between plain and agreement verbs. The point here is to see if the claim that only a (small) subset of verbs show agreement still holds true when the definition given in (2) is considered. An important question here is: how pervasive is agreement?

Additionally, it is desirable to identify what the features are that actually block agreement and their nature. Are some verbs not capable of showing agreement because of some syntactic or semantic reason or because of their morphophonological specification?

\subsection{The pervasiveness of agreement}

In order to identify the pervasiveness of agreement in Libras, we analyzed 584 Libras verbs extracted from a Libras dictionary (Capovilla et al. 2017). ${ }^{4}$ These verbs were classified in terms of transitivity, agreement pattern (assuming the classical Paddenian classification), phonological shape and event structure by the deaf informants, who are Libras professors and have some training in linguistics, and the researchers. The most relevant categories for the discussion we are outlining here are the following ones:

Agreement pattern:

a. Plain verbs

b. Agreement verbs

i. Single agreement verbs

ii. Double agreement verbs (regular)

iii. Backward agreement verbs

iv. Spatial verbs

(4) Phonological shape:

a. [PATH] feature

b. Body-anchoring

After analyzing each verb in terms of its agreement pattern, we conflated all the agreement categories into one, called "agreement". The results are given in Figure 6.

\footnotetext{
${ }^{4}$ The classification of the verbs was done in collaboration with 11 deaf people from different geographic regions of Brazil. 3 deaf people were regular consultants and classified most of the verbs analyzed here. The other 9 deaf informants provided some occasional assistance, because some of the verbs found in the dictionary were from a specific geographic region and were not known by the 3 main informants.
} 
Figure 6: Quantitative analysis of the verbs in Libras.

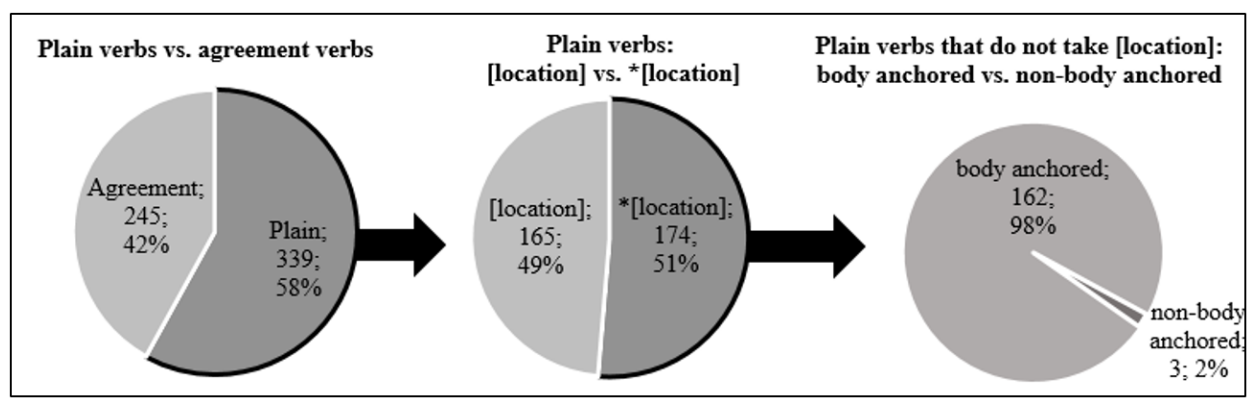

Our first question on the pervasiveness of agreement is directly answered from the fact that $42 \%$ of the verbs are those traditionally called agreement verbs (whether spatial, regular, backward, single or double) and 58\% are "plain" verbs. These numbers alone contradict the argument that "the agreement process in sign languages is restricted to a smaller set of verbs, whereas agreement in spoken languages, if it is marked at all, is usually marked on the whole set of verbs" (Mathur and Rathmann 2012, p. 152). This claim is at least questionable, considering that almost half of our verbs are "agreeing".

Further, if we consider co-localization to be true agreement, we need to see how many of those "plain" verbs can show change of location in order to match the loci of their arguments. The result is that $49 \%$ of the "plain" verbs can indeed show location matching, while $51 \%$ cannot, as seen in Graphic 1. Because "plain" verbs do not have a [direction] type of path, they only have one slot for agreement, so they can only match the location of one single argument. We will go back to this discussion later.

\subsection{Restriction for agreement}

One interesting question is what blocks agreement in those verbs that cannot match the loci of their arguments. This is easily answered if we look at their phonological shape. $98 \%$ of the plain verbs that cannot be co-localized are body-anchored. This indicates that a verb will show agreement unless it is already fully specified for location.

What do we mean by fully specified for location? Assuming the Prosodic Model (Brentari 1998) we can predict which verbs cannot take their argument's location specification from their phonological features (see also Figure 7):

(5) Restriction for agreement:

A verb can be co-localized unless it is already lexically valued for one of the following body 2 nodes:

- head

- bodyo

- arm

Curiously, the remaining three exceptions of verbs that are not lexically specified under these three nodes and still cannot take location features from an argument are the verbs given in Figure 8. Notice that although they are not body-anchored per se, they must be pronounced close to the body and they are also highly iconic. 
Figure 7: The Place of Articulation (POA) structure in the Prosodic Model (Brentari 1998). The nodes that are marked by dashed lines are the ones that block agreement when lexically specified.

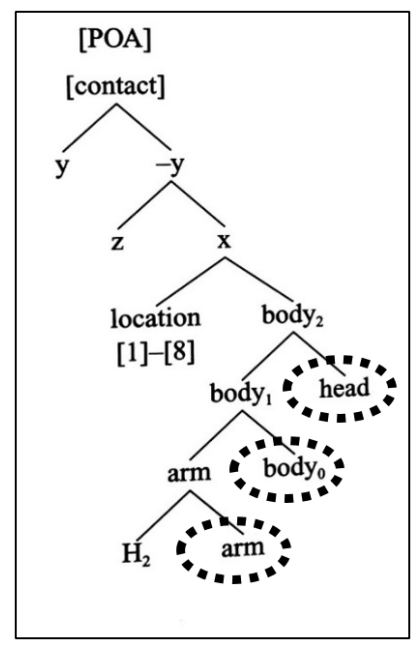

Figure 8: The verbs MAKE-EFFORT, MEDITATE and BEG are the only exceptions found in our data that are not body-anchored and cannot be co-localized.

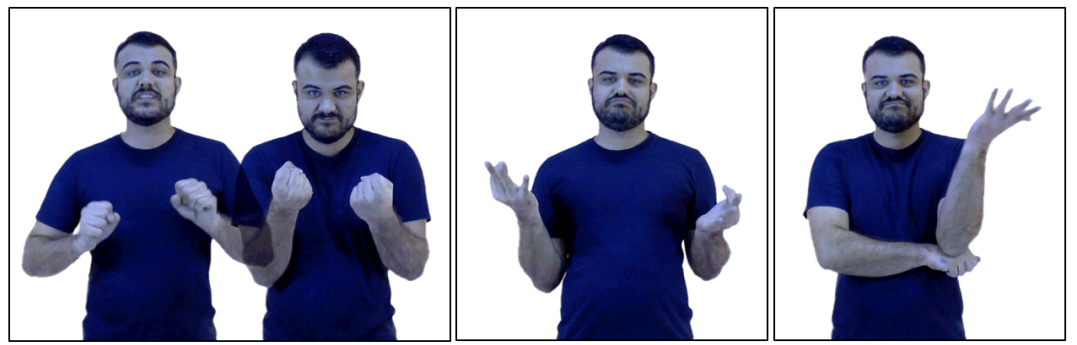

\subsection{What about path?}

Additional relevant phonological information is the type of path feature that the verb carries. We have mentioned so far that the path movement in the traditional agreeing verbs has been analyzed as the agreement marker in sign languages. Here we challenge this notion, by claiming that the true exponent of agreement is the matching of location. However, the type of path feature is indeed relevant for agreement as it predicts how many slots for co-localization, hence agreement, a verb will carry.

Although it has been claimed that traditional agreement verbs have path, a more finegrained phonological analysis helps to avoid terminological misunderstandings. In the Prosodic Model, five types of path features are described. We discuss two of them, as they are the most representative ones: [direction] and [tracing], although all five types are illustrated in Figure 9. The following definitions are extracted from Brentari (1998, pp. 136-137):

(6) [direction]

a phonologically specified straight path executed at a $90^{\circ}$ angle to (notated $[>\mid]$ ) or from (notated $[\mid>]$ ) a point in a plane of articulation, either from such a point or to such a point. 
(7) [tracing]

a line with an arc, straight, or circle shape articulated with respect to a single point within a plane.

Figure 9: The surface realization of path features (Brentari 1998, p. 137).

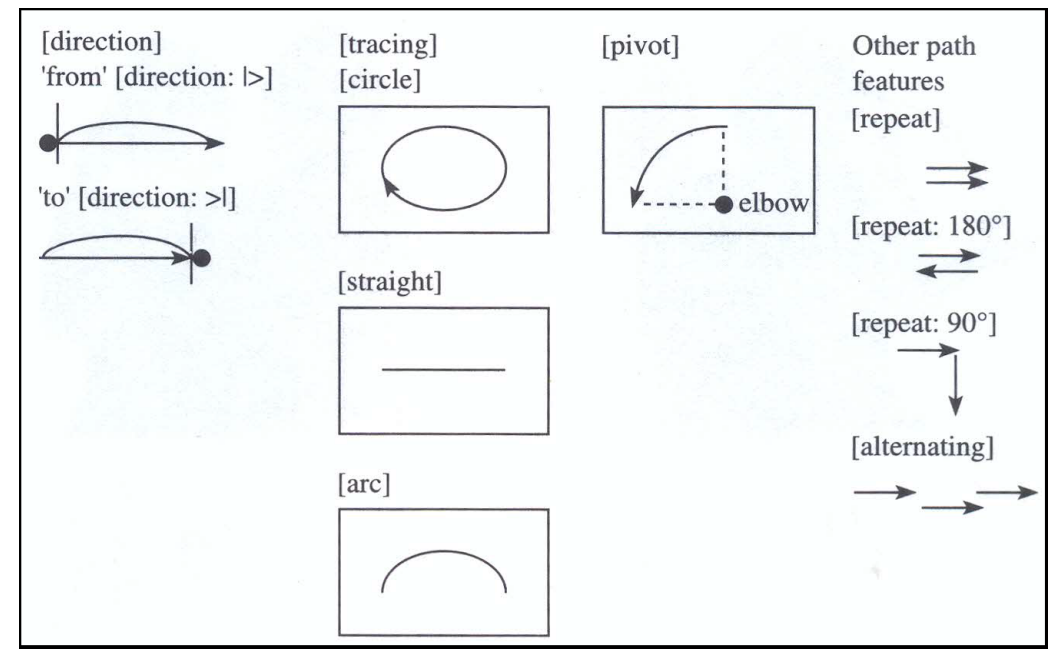

What is special about traditional agreement verbs is not that they are the only ones that can show agreement, but that they are capable of agreeing with two arguments (usually subject and object) because of their [direction] type of path. Once they have direction, they have two slots for Place of Articulation features, one in each timing unit under their Prosodic Feature representation (Figure 10):

Figure 10: Verbs with [direction] can bear two different set of PoA specifications in their phonological structure, one in each timing unit. Therefore, they have two possible slots for agreement.

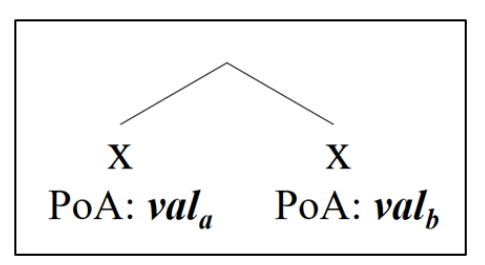

On the other hand, so-called "plain" verbs do not have [direction]. They have [tracing] or one of the other types of path features. As a consequence, they are articulated with respect to a "single point within a plane", as stated by Brentari (1998, p. 136), and can take location specification from only one argument.

Notice, however, that the path features do not mark agreement by themselves. They are, as stated before, related to the event properties of the predicate (see Wilbur $(2008,2010)$ for a more extensive discussion of event properties, such as activities, achievements, and accomplishments). The path conveys some semantic notions, such as the temporal unfolding of the event; and even the transfer semantics claimed to be central to agreement (Bos 2017; Meir 1998b, 2002) is just one (sub)type of event for which properties are inferable from the path movement. 


\section{The layering of visual information in the internal structure of the verb}

Treating co-localization as the true and only agreement marker allow us to make a bigger claim regarding the internal structure of the verb:

(8) The layering of visual information in the verb structure:

Different morphological operations will target specific nodes of the phonological structure of the verb.

A simplified version of the internal structure of the verb is provided in Figure 11 with the morphological operations assigned to their respective target node.

Figure 11: The layering of visual information in the internal structure of the verb.

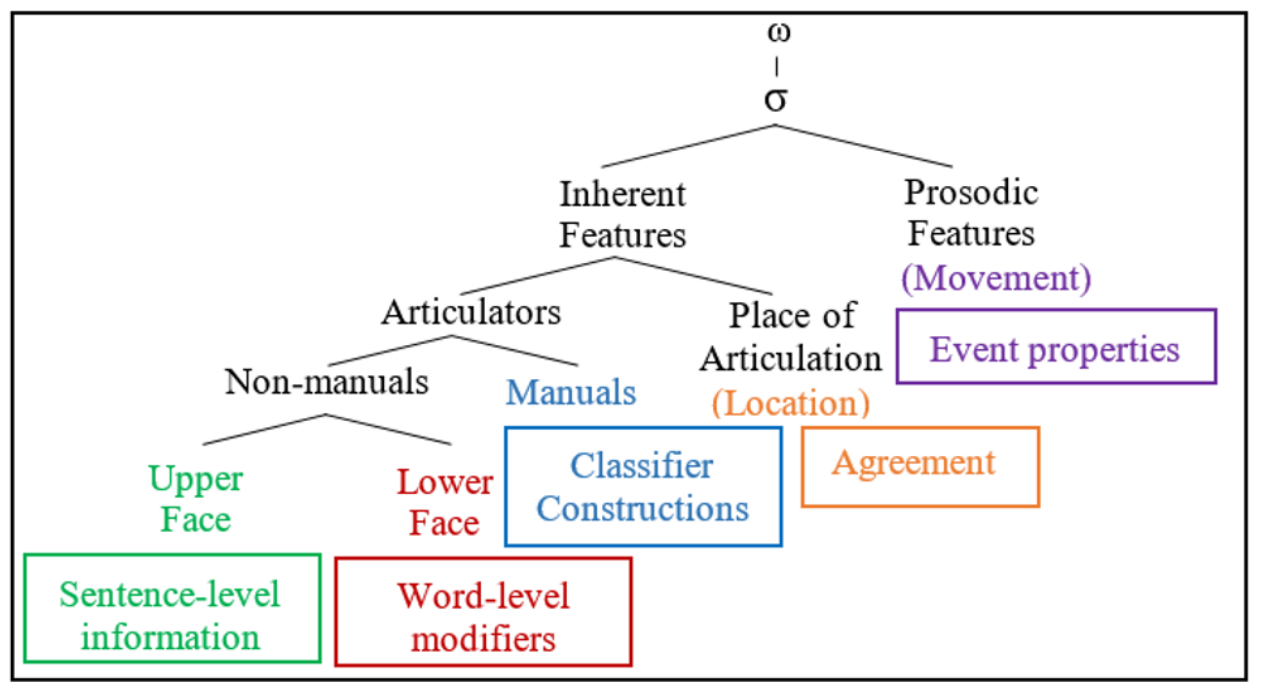

Before discussing in detail the internal structure of the verb, let us bring a definition of layering:

Layering is the linguistic organizational mechanism by which multiple pieces of information can be sent simultaneously; it requires that the articulation of each piece cannot interfere with the others. Thus, layering is a conspiracy of form (articulation) and meaning to allow more than one linguistically meaningful unit of information (morpheme) to be efficiently transferred simultaneously (Wilbur 2003a, p. 334).

In terms of manual layering, the classical examples come from the fact that sign languages largely exploit the possibility of using two hands independently and, therefore, different pieces of information can be transmitted by each hand (Battison 1978). Layering is also found in classifiers constructions and even verb agreement has been claimed to be a kind of layering in sign languages (Wilbur 2003a, pp. 334-336).

Layering is also a design feature of the non-manual marking systems attested in sign languages. The most basic layering of non-manual information is seen when you have the separation of grammatical and affective non-manual expressions (Wilbur 2000). Moreover, grammatical non-manual markings are usually coordinated with syntactic constituents, e.g. 
the spreading of the negative headshake (Veinberg and Wilbur 1990) or are limited to a specific phrase when providing adjectival or adverbial information (Liddell 1978, 1980).

The idea here is to expand the concept of layering to the verb structure and, therefore, to the verbal morphology. Instead of assuming that morphological operations can change the whole structure of the verb, we claim, based on previous studies in the literature, that morphological processes target specific parts of verb morphology.

Starting with the non-manual domain, there is an interesting specialization between upper and lower-face. Lower-face markers usually are related to word-level modifications, adverbial in the case of verbs (Liddell 1978, 1980; Wilbur 2003a); and upper-face markers are associated with specific syntactic structures (Aarons 1994; Bahan 1996; Baker-Shenk 1983; Liddell 1986; Wilbur 1994, 1995; inter alia).

The manual node consists of the inherent handshape features of the dominant hand and the non-dominant hand ( $\mathrm{H} 1$ and $\mathrm{H} 2$, respectively). Modifications of the manual tier constitute the core morphological process that creates classifier constructions. Different proposals have been suggested that identify different handshapes associated to specific types of classifiers (Engberg-Pedersen 1993; Supalla 1982, 1986). There is even a correlation between handshape type and argument structure (Benedicto and Brentari 2004).

What we emphasize here is the disentanglement of the functions of location and movement in the verb structure. Movement modifications are associated to the event structure of the predicate and aspectual modifications (Wilbur 2003b, 2008, 2009, 2010).

Location modifications (co-localization) in the verb are related to agreement; as the definition given in (2) and repeated below:

(9) Definition of verb agreement in sign languages:

A verb shows agreement with its argument(s) when the location of the verb is changed in order to match the location of the argument(s), a process called co-localization.

\section{Final remarks}

In this paper, we claimed that location is the true agreement marker in sign languages, using data from Libras. The main corollaries of our analysis are:

- Agreement is analyzed as the matching of location between the verb and its argument(s) (co-localization).

- Agreement is everywhere! No longer exclusive to a subset of verbs.

- A verb shows agreement unless it is phonologically restricted not to do so. The set of phonological features that block agreement is easily identified.

- The path movement ([direction]) found in traditional agreement verbs is actually related to the event properties of the predicate and to aspectual modifications.

- Disentangling location from movement contributes to a fine-grained description of the layering of visual information within the verb structure.

\section{References}

Aarons, Debra. 1994. “Aspects of the syntax of American Sign Language”. Ph.D. dissertation, Boston University.

Bahan, Benjamin. 1996. "Non-manual realization of agreement in ASL”. Ph.D. dissertation, Boston University. 
Baker-Shenk, Charlotte Lee. 1983. "A micro-analysis of the non-manual components of questions in American Sign Language”. Ph.D. dissertation, University of California, Berkeley.

Battison, Robbin. 1978. Lexical borrowing in American Sign Language. Silver Spring, MD: Linstok Press.

Benedicto, Elena, and Diane Brentari. 2004. "Where did all the arguments go?: Argumentchanging properties of classifiers in ASL". Natural Language and Linguistic Theory 22 (4): 743-810.

Bergman, Brita. 1980. "On localization in the Swedish Sign Language". In Papers from the First International Symposium on Sign Language Research, ed. by Inger Ahlgren and Brita Bergman, 81-92. Stockholm: Swedish Deaf Association.

Bos, Heleen F. 2017. "An analysis of main verb agreement and auxiliary agreement in NGT within the theory of Conceptual Semantics (Jackendoff 1990)". Sign Language \& Linguistics 20 (2): 228-252.

Brentari, Diane. 1998. A prosodic model of sign language phonology. 376. Cambridge MA: MIT Press.

Capovilla, Fernando César., Walkiria Duarte Raphael, Janice Gonçalves Temoteo, and Antonielle Cantarelli Martins. 2017. Dicionário da Língua de Sinais do Brasil: A Libras em Suas Mãos. São Paulo: Edusp.

Costello, Brendan. 2015. "Language and modality: Effects of the use of space in the agreement system of Lengua de Signos Española (Spanish Sign Language)”. PhD Dissertation, University of Amsterdam and the University of the Basque Country.

Engberg-Pedersen, Elisabeth. 1993. Space in Danish Sign Language. Hamburg: Signum Verlag.

Fischer, Susan D., and Bonnie Gough. 1978. "Verbs in American Sign Language". Sign Language Studies 18 (1): 17-48.

Fischer, Susan D., and Harry van der Hulst. 2003. "Sign language structures”. In The Oxford Handbook of Deaf Studies, Language, and Education, ed. by Marc Marschark and Patricia E Spencer, 319-331. New York: Oxford University Press.

Janis, Wynne D. 1995. “A crosslinguistic perspective on ASL verb agreement”. In Language, Gesture, and Space, ed. by Karen Emmorey and Judy Reilly, 195-224. Psychology Press.

Liddell, Scott K. 1978. "Nonmanual signals and relative clauses in American Sign Language”. In Understanding sign language through sign language research, ed. by P Siple, 59-90. New York: Academic Press.

— . 1980. American sign language syntax. The Hague: Mouton.

— . 1986. "Head thrust in ASL conditional marking". Sign Language Studies Fall 1986 (52): 243-262.

— . 2000. "Indicating verbs and pronouns: Pointing away from agreement". In The Signs of Language Revisited: An Anthology To Honor Ursula Bellugi and Edward Klima, ed. by Karen Emmorey and Harlan L. Lane, 303-320. Mahwah, NJ: Lawrence Erlbaum.

— . 2011. "Agreement disagreements". Theoretical Linguistics 37 (3-4): 161-172.

Lillo-Martin, Diane, and Richard P. Meier. 2011. 'On the linguistic status of 'agreement' in sign languages”. Theoretical Linguistics 37 (3-4): 95-141. 
Mathur, Gaurav, and Christian Rathmann. 2010. "Verb agreement in sign language morphology”. In Sign Languages, ed. by Diane Brentari, 173-196. Cambridge: Cambridge University Press.

— . 2012. "Verb agreement". In Sign Language: An international handbook, ed. by Roland Pfau, Markus Steinbach, and Bencie Woll, 136-157. Berlin/Boston: De Gruyter Mouton.

Meir, Irit. 1998a. "Syntactic-semantic interaction in Israeli Sign Language verbs: The case of backwards verbs”. Sign Language \& Linguistics 1 (1): 3-37.

— . 1998b. "Thematic structure and verb agreement in Israeli Sign Language”. Ph.D. Thesis, Hebrew University of Jerusalem.

— . 2002. "A cross-modality perspective on verb agreement". Natural Language and Linguistic Theory 20 (2): 413-450.

Neidle, Carol, Kegl; Judy, Dawn Maclaughlin, Benjamin Bahan, and Robert G Lee. 2000. The Syntax of American Sign Language: Functional categories and hierarchical structure. Cambridge, MA: The MIT Press.

Padden, Carol. 1988. Interaction of morphology and syntax in American Sign Language. New York \& London: Garland Publishing.

Pfau, Roland, Martin Salzmann, and Markus Steinbach. 2011. "A non-hybrid approach to sign language agreement”. In FEAST 2011, 1-12. 2. Venice, Italy.

Quadros, Ronice Müller. 1999. "Phrase structure of Brazilian Sign Language”. PhD thesis, Pontifícia Universidade Católica do Rio Grande do Sul.

Quadros, Ronice Müller, and Josep Quer. 2008. "Back to back(wards) and moving on: On agreement, auxiliaries and verb classes”. In Sign Languages: Spinning and unraveling the past, present, and future. Forty-five papers and three posters from the 9th Theoretical Issues in Sign Language Research Conference, Florianopolis, Brazil, December 2006, ed. by Ronice Müller Quadros, 530-551. Petrópolis: Arara Azul.

Quadros, Ronice Müller, Deonísio Schmitt, Juliana Lohn, and Tarcísio de Arantes Leite. Corpus de Libras. http: //corpuslibras . ufsc. br/.

Quer, Josep. 2011. "When agreeing to disagree is not enough: Further arguments for the linguistic status of sign language agreement”. Theoretical Linguistics 37 (3-4): 189-196.

Rathmann, Christian, and Gaurav Mathur. 2002. "Is verb agreement the same crossmodally?" In Modality and structure in signed and spoken language, ed. by Richard P. Meier, Kearsy Cormier, and David Quinto-Pozos, 370-404. New York: Cambridge University Press.

Sandler, Wendy, and Diane Lillo-Martin. 2006. Sign Language and linguistic universals. New York: Cambridge University Press.

Smith, Wayne H. 1990. "Evidence for auxiliaries in Taiwan Sign Language”. In Theoretical Issues in Sign Language Research, Vol. 1, ed. by Susan D. Fischer and Patricia Siple, 211228. Chicago: University of Chicago Press.

Supalla, Ted. 1982. "Structure and acquisition of verbs of motion and location in American Sign Language”. Ph.D. dissertation, University of California, San Diego.

— . 1986. "The classifier system in American Sign Language". In Noun classes and categorization, ed. by Colette Craig, 181-214. Amsterdam \& Philadelphia: John Benjamins. 
Thompson, Robin, Karen Emmorey, and Robert Kluender. 2006. “The relationship between eye gaze and verb agreement in American Sign Language: An eye-tracking study”. Natural Language and Linguistic Theory 24 (2): 571-604.

Veinberg, Silvana C, and Ronnie B. Wilbur. 1990. "A linguistic analysis of the negative headshake in American Sign Language”. Sign Language Studies 68:217-243.

Wilbur, Ronnie B. 1994. "Eyeblinks and ASL phrase structure”. Sign Language Studies 84 (1): 221-240.

— . 1995. "What the morphology of operators looks like: A formal analysis of ASL browraise". In FLSM VI: Proceedings of the Sixth Annual Meeting of the Formal Linguistics Society of Mid-America: Vol. 2. Syntax and semantics/pragmatics, ed. by L. Gabriele, D. Hardison, and R. Westmoreland, 67-78. Bloomington: Indiana University Linguistics Club.

— . 2000. "Phonological and prosodic layering of nonmanuals in American Sign Language". In The Signs of Language revisited: An anthology to honor Ursula Bellugi and Edward Klima, ed. by Karen Emmorey and Harlan Lane, 213-241. Hillsdale, NJ: Lawrence Erlbaum. ISBN: 0805832467.

— . 2003a. "Modality and the structure of language: Sign languages versus signed systems". In Oxford Handbook of Deaf Studies, Language, and Education, ed. by Marc Marschark and Patricia E Spencer, 332-346. New York: Oxford University Press.

— . 2003b. "Representation of telicity in ASL". Chicago Linguistic Society 39 (1992): 354-368.

— . 2008. "Complex predicates involving events, time, and aspect: Is this why sign languages look so similar?” In Signs of the time: Selected papers from TISLR 2004, ed. by Josep Quer, 217-250. Hamburg: Signum--Verlag.

— . 2009. "Productive reduplication in a fundamentally monosyllabic language". Language Sciences 31 (2-3): 325-342.

— . 2010. "The semantics-phonology interface”. In Sign languages: A Cambridge language survey, ed. by Diane Brentari, 355-380. Cambridge: Cambridge University Press.

— . 2013. "The point of agreement: Changing how we think about sign language, gesture, and agreement”. Sign Language \& Linguistics 16 (2): 221-258. 